\title{
Finding an Alternative for the Surgical Clips-based Delineation of Tumor Bed Boost Volume for Radiotherapy after Breast Conserving Surgery: A Prospective Comparative Study
}

\author{
Mrutyunjayarao Muvvala1, Pragna Sagar Rapole', Gunaseelan Karunanithi', \\ Vijayaprabhu Neelakandan', Kadambari Dharanipragada ${ }^{2}$
}

${ }^{1}$ Deparment of Radiation Oncology, Regional Cancer Centre, Jawaharlal Institute of Post-Graduate Medical Education and Research (JIPMER), Puducherry, India. ${ }^{2}$ Department of General Surgery, Regional Cancer Centre, Jawaharlal Institute of PostGraduate Medical Education and Research (JIPMER), Puducherry, India.

\begin{abstract}
Background: Radiotherapy after breast conserving surgery includes irradiation of whole breast and regional lymphatic areas which is followed by a boost to the tumor bed. Several different techniques have been proposed for delineation of tumor bed for boost. The purpose of the study was to identify the best method for localizing the tumor bed. Methods: 21 patients with histologically proven stage I and II infiltating ductal carcinoma of breast who underwent breast conserving surgery were included in the study. We delineated the boost volumes using five different techniques viz., patients' self-localization, surgeon's localization, pre-op CT based, scar-based and surgical clips based. The surgical clips-based volume is taken as a standard volume and the other volumes were compared with it. The outcome measures studied were the mean overlap volumes, the mean volume of surgical clips based volume missed by the other PTVs, the mean volumes of breast tissue outside the clips based PTV that could have been irradiated by the other PTVs. Results: None of the PTV volumes had good concordance with the surgical clips-based volume (PTV1). The best volume overlap was with patient's self-localization (PTV3) albeit only being $34 \%$. The scar-based localization volume had the least overlap with PTV1 (23\%). The patients' self-localization volume (PTV3) had the highest amount of breast tissue included outside PTV1 (64cc) and preop CT based volume (PTV4) included the least (42cc). Conclusion: Delineation of boost volume using surgical clips augmented by the simulation CT should be the standard technique for boost bed irradiation.
\end{abstract}

Keywords: Breast conservation therapy- tumor bed boost- surgical clips based delineation- CT based delineation

Asian Pac J Cancer Care, 5 (4), 303-306
Submission Date: 06/14/2020Ａcceptance Date: 11/08/2020

\section{Introduction}

Breast conservation therapy is the standard of care for operable early-stage breast cancer which includes removal of the primary tumor with adequate margin followed by radiotherapy. Radiotherapy includes irradiation of whole breast and regional lymphatic areas which is followed by a boost to the tumor bed. About $50-60 \%$ of all local recurrences occur at or near the initial site of the tumor mandating the need for tumor bed boost.

The importance of boost to the tumor bed in reducing local recurrence was supported by two randomized trials
[1-2]. But the definition of tumor bed volume for boost was not clearly defined [3]. As several publications questioned the high rate of inadequate tumor bed coverage associated with using scar and clinical data [4-5]. CT based planning became a popular method of boost volume definition [3]. Scar based boost planning results in inadequate tumor bed coverage delineation when the surgical approaches have concentrated mainly on cosmesis by giving a small/ peri areolar incision.

The purpose of the study was to identify the best

Corresponding Author:

Dr. Gunaseelan Karunanithi

Department of Radiation Oncology, Regional Cancer Centre, Jawaharlal Institute of Post-Graduate Medical Education and Research (JIPMER),

Puducherry, India.

Email: gunapgi@gmail.com 
method for localizing the tumor bed. Surgical clips-based delineation was taken as standard and the other methods were compared to it in terms of tumor bed coverage and doses to the organ at risk.

\section{Materials and Methods}

21 patients with histologically proven stage I and II infiltating ductal carcinoma of breast who underwent breast conserving surgery were included in the study. Patients with contraindications for breast conserving therapy viz., microcalcifications on a mammogram, multicentric disease, previous irradiation to chest wall, pregnancy, lactation, metastatic disease, cardiac and pulmonary disease, and other malignancy were excluded.

We delineated the boost volumes using five different techniques viz., patients' self-localization, surgeon's localization, pre-op CT based, scar-based and surgical clips based. The surgical clips-based volume is taken as a standard volume and the other volumes were compared with it in terms of concordance. The outcome measures studied were the mean overlap volumes of PTVs 2-5 with PTV1, the mean volume of PTV1 missed by the other PTVs, the mean volumes of breast tissue outside the PTV1 that could have been irradiated by the other PTVs.

\section{Method of delineating the volumes}

Whole breast CTV was drawn based on the RTOG consensus guidelines. Planning target volumes (PTVs) were drawn by giving $0.5 \mathrm{~cm}$ margin to the CTVs and cropped $3 \mathrm{~mm}$ from the skin surface.

The boost volumes were labelled CTVs 1-5 depending on the method used as described below.

\section{a. Surgical clips based (CTV1)}

After the excision of tumor, the surgical clips were placed in the four corners of the tumor cavity and in the tumor bed. These clips were used to delineate the CTV1. CTV was drawn $1 \mathrm{~cm}$ supero-inferiorly and $0.5 \mathrm{~cm}$ around the clips. The volume is expanded to include the seroma volume as seen on the post-operative simulation CT. This volume was taken as a standard with which the other volumes were compared.

b. Surgeon's localization (CTV2), Patients' selflocalization (CTV3) and pre-op CT based (CTV4).

Before starting oncological treatment, the patients were instructed to localize the lump they can feel in the breast by pointing at each of the lump's border which is then marked on the skin. On the same day, the operating surgeon would examine the patient and mark the tumour on the skin. Both the markings were wired and a CT image of the patient in the treatment position was taken. After lumpectomy, simulation CT was taken in the same position and both the images will be registered. The CTV2 and CTV3 volumes were drawn on the simulation CT using the information from the wire markings placed on the pre-op CT image. The area of the breast adjacent to the radiopaque wire markings is delineated. This is extended down with the same width to the level of preoperative tumor depth. CTV4 was drawn using the preoperative tumour seen on the CT plus $5 \mathrm{~mm}$ margin.

c. Scar based localization (CTV5)

Postoperative scar was wired over skin before CT simulation. The area of the breast adjacent to the radiopaque wire markings is delineated. This is extended down with the same width to the level of preoperative tumor depth.

\section{Statistical Analysis}

The volumes were compared using One Way Analysis of Variance (ANOVA) and Two-Way Analysis of Variance (ANOVA) along with post-hoc analysis with Bonferroni test. All the results were compared at 5\% level of significance, and the entire analysis was done by using IBM SPSS 19.0 version and MS Excel Office 365.

\section{Results}

A total of 21 patients were recruited into the study. 9 were left sided breast cancer and 12 were right sided. $95 \%$ of the tumors were of size T2. Table 1 gives the list of tumor characteristics.

The PTV1 (surgical clips-based volume) was considered as the standard and the other volumes were compared with it. The PTV1 was the largest of all the PTVs with mean of $211 \mathrm{cc}$. Scar based localization volume (PTV5) was the smallest with a mean volume of only $101 \mathrm{cc}$. None of the PTV volumes had good concordance with the scar-based volume (PTV1). The best volume overlap was with patient's self-localization (PTV3) albeit only being $34 \%$. The scar-based localization volume had the least overlap with PTV1 (23\%). All the other PTVs had some amount of breast tissue being included outside the PTV1 volume. The self-localization volume (PTV3) had the highest amount of breast tissue included outside PTV1 (64cc) and pre-op CT based volume (PTV4) included the least $(42 \mathrm{cc})$. The target volume coverage, miss, and volume of normal breast tissue outside PTV1 that is included among the different delineation techniques are described in the Table 2.

Table 1. Tumor Characteristics

\begin{tabular}{lccc}
\hline Tumor/Nodal status & & No. & $\%$ \\
\hline T size & T1 & 1 & 5 \\
\multirow{3}{*}{ N status } & T2 & 20 & 95 \\
\multirow{3}{*}{ stage } & N0 & 14 & 67 \\
\multirow{3}{*}{ Site of the tumor } & N1 & 7 & 33 \\
& 1 & 1 & 5 \\
& 2 & 20 & 95 \\
& Upper outer & 15 & 72 \\
& Upper inner & 3 & 14 \\
& Lower inner & 0 & 0 \\
\hline
\end{tabular}


Table 2. Localization Methods-target Volume Coverage, Miss, and Volume of Normal Breast Tissue Outside PTV1 that is Included

\begin{tabular}{|c|c|c|c|c|c|}
\hline Method & $\begin{array}{l}\text { Mean Volume } \\
\text { (cc) }\end{array}$ & $\begin{array}{l}\text { Overlap } \\
\text { (cc) }\end{array}$ & $\begin{array}{l}\text { with PTV1 } \\
(\%)\end{array}$ & $\begin{array}{l}\text { Target volume missing } \\
\qquad(\%)\end{array}$ & $\begin{array}{l}\text { Volume of breast tissue included outside PTV1 } \\
\qquad \text { (cc) }\end{array}$ \\
\hline PTV1 & 211 & - & - & - & - \\
\hline PTV2 & 112 & 56 & 28 & 72 & 56 \\
\hline PTV3 & 129 & 65 & 34 & 66 & 64 \\
\hline PTV4 & 104 & 62 & 29 & 71 & 42 \\
\hline PTV5 & 101 & 44 & 23 & 77 & 57 \\
\hline
\end{tabular}

\section{Discussion}

Adjuvant radiotherapy is an integral part of breast conservative therapy [6]. The benefit of whole breast adjuvant radiation was established by many randomized trials [7-9]. The current clinical practice is to deliver dose up to 45 - 50 Gy to the whole breast which reduces local recurrences at 5 years to one-third; that is from 30 to $50 \%$ down to 10 to $15 \%$. These recurrences occurred mostly nearer to the original lesion. This warrants additional irradiation to the tumor bed. Van Limbergen et al. demonstrated from the analysis of dose-response curve that an addition of 15 Gy would reduce the local recurrence by a factor of 2 [10]. Several studies have demonstrated the dose-response effect above the dose of $50 \mathrm{~Gy}$ in retrospective as well as in prospective randomized trials [2-11]. Tumor bed boost of $16-20 \mathrm{~Gy}$ is recommended so that the tumor bed should receive a dose of 60 - 65 Gy.

Irradiation of tumor bed boost will result in decreased ipsilateral tumor recurrences. It is essential to accurately delineate the boost volume for delivering radiotherapy. Several techniques have been proposed but the boost volume delineated using the surgical clips placed during excision is considered standard. However, except for the randomized trial conducted by the Polgar et al., most of the other studies examining the benefit of boost did not use the surgical clips for delineation of the boost target volume. Some institutes may not have facilities for surgical clips placement and may need to use other techniques to delineate the boost volume. Several studies have been done examining the merits and demerits of other techniques of delineating like scar-based delineation, clinical examination or CT based delineation [12-14].

Although surgical clips are considered standard, the facilities may not available in many institutes or the cost of clips may pose hinderance. In this study, we intended to compare this technique with other simple clinical exam based or scar-based localisation methods which if found similar could be used routinely. Unfortunately, all the other methods of delineation had significantly different volumes and substantial geographical miss compared to surgical clips-based technique.

Machtay and colleagues have done a study on 316 electron boost simulation films to test the accuracy of different methods of volume selection based on scar location by comparing them with surgical clips [4]. All the methods were inaccurate with inadequate coverage ranging from $10-88 \%$ depending on the method and margins used. Another similar study done by Kovner et al. also showed that there is a significant miss of tumor bed volume by using scar-based localization [5]. Scar based volumes were 1.4 times larger than clips-based volumes. Scar based target volume delineation shows poor volume overlap (23\%) with surgical clip volume in our study when compared to Kovner et al. study (70\%). So, the boost volume defined by scar location may lead to geographical miss and increased local recurrences, but this has not been studied clinically.

CT scan is also used in many institutes for delineating the boost where surgical clips placement is not available. Tumor volume seen on the preoperative CT scan and the seroma cavity in the post-operative CT scan can be used to create the CTV. The main disadvantage with $\mathrm{CT}$ is the uncertainty of the seroma volume which may expand, contract or displace during healing process after surgery. However, CT when combined with surgical clips will greatly increase the accuracy of bed delineation. MRI may be more accurate in identifying smaller cavities but the cost, availability and difficulties in registration limits its use routinely.

In a study done by Fawzy et al., they compared 4 methods of delineation viz., clinically based, CT based, ultrasound based and surgical clips.[14] They have used geographical miss index (GMI), normal tissue index (NTI) and overlap index (OI) to compare the techniques. They found significant differences in the indices between the techniques and compared to surgical clips, all the other techniques had significant geometrical miss and excessive normal tissue irradiation leading to a conclusion of surgical clips to be the standard technique for tumor bed delineation.

In conclusion, accurate delineation of tumor bed is essential to reduce the ipsilateral breast tumor recurrences. There were significant differences in the volumes drawn using clinical, scar based or CT based techniques compared to the surgical clips. Other methods of delineation also had substantial geographical miss of the target and excessive irradiation of the normal breast tissue. Delineation of boost volume using surgical clips augmented by the simulation CT should be the standard technique for boost bed irradiation. 


\section{Acknowledgements}

We like to thank Mr Vishnuvardhan R, Statistican, Pondicherry University for helping in statistical analysis of our study.

\section{References}

1. Romestaing P, Lehingue Y, Carrie C, Coquard R, Montbarbon X, Ardiet JM, Mamelle N, Gérard JP. Role of a 10-Gy boost in the conservative treatment of early breast cancer: results of a randomized clinical trial in Lyon, France.. Journal of Clinical Oncology. 1997 03;15(3):963-968. https://doi. org/10.1200/jco.1997.15.3.963

2. Bartelink H, Horiot J, Poortmans PM, Struikmans H, Van den Bogaert W, Fourquet A, Jager JJ, Hoogenraad WJ, Oei SB, Wárlám-Rodenhuis CC, Pierart M, Collette L. Impact of a Higher Radiation Dose on Local Control and Survival in Breast-Conserving Therapy of Early Breast Cancer: 10Year Results of the Randomized Boost Versus No Boost EORTC 22881-10882 Trial. Journal of Clinical Oncology. 200708 01;25(22):3259-3265. https://doi.org/10.1200/ jco.2007.11.4991

3. Campana F, Kirova YM, Rosenwald J, Dendale R, Vilcoq JR, Dreyfus H, Fourquet A. Breast radiotherapy in the lateral decubitus position: A technique to prevent lung and heart irradiation. International Journal of Radiation Oncology*Biology*Physics. 2005 04;61(5):1348-1354. https://doi.org/10.1016/j.ijrobp.2004.08.051

4. Machtay M, Lanciano R, Hoffman J, Hanks GE. Inaccuracies in using the lumpectomy scar for planning electron boosts in primary breast carcinoma. International Journal of Radiation Oncology*Biology*Physics. 1994 08;30(1):43-48. https:// doi.org/10.1016/0360-3016(94)90517-7

5. Kovner F, Agay R, Merimsky O, Stadler J, Klausner J, Inbar M. Clips and scar as the guidelines for breast radiation boost after lumpectomy. European Journal of Surgical Oncology (EJSO). 1999 Oct;25(5):483-486. https://doi.org/10.1053/ ejso. 1999.0683

6. Smith BD, Bellon JR, Blitzblau R, Freedman G, Haffty B, Hahn C, Halberg F, Hoffman K, Horst K, Moran J, Patton C, Perlmutter J, Warren L, Whelan T, Wright JL, Jagsi R. Radiation therapy for the whole breast: Executive summary of an American Society for Radiation Oncology (ASTRO) evidence-based guideline. Practical Radiation Oncology. 2018 05;8(3):145-152. https://doi.org/10.1016/j. prro.2018.01.012

7. Fisher B, Anderson S, Bryant J, Margolese RG, Deutsch M, Fisher ER, Jeong J, Wolmark N. Twenty-Year Followup of a Randomized Trial Comparing Total Mastectomy, Lumpectomy, and Lumpectomy plus Irradiation for the Treatment of Invasive Breast Cancer. New England Journal of Medicine. 2002 Oct 17;347(16):1233-1241. https://doi. org/10.1056/nejmoa022152

8. Arriagada R, Rutqvist LE, Mattsson A, Kramar A, Rotstein $\mathrm{S}$. Adequate locoregional treatment for early breast cancer may prevent secondary dissemination.. Journal of Clinical Oncology. 1995 Dec;13(12):2869-2878. https://doi. org/10.1200/jco.1995.13.12.2869

9. Haviland JS, Owen JR, Dewar JA, Agrawal RK, Barrett J, Barrett-Lee PJ, Dobbs HJ, Hopwood P, Lawton PA, Magee BJ, Mills J, Simmons S, Sydenham MA, Venables K, Bliss JM, Yarnold JR. The UK Standardisation of Breast Radiotherapy (START) trials of radiotherapy hypofractionation for treatment of early breast cancer: 10year follow-up results of two randomised controlled trials.
The Lancet Oncology. 2013 Oct;14(11):1086-1094. https:// doi.org/10.1016/s1470-2045(13)70386-3

10. Van Limbergen E, Reynders A, Van den Bogaert W. The usefull boost range (UBR) concept judges the ballistic selectivity of electron beams (EB) versus brachytherapy (BT) in the boost techniques of breast conserving therapy. Eur J Cancer. 1998;34:S57.

11. Poortmans P, Collette L, Bartelink H, Struikmans H, Van den Bogaert W, Fourquet A, Jager J, Hoogenraad W, Müller R, Dubois J, Bolla M, Van Der Hulst M, Wárlám-Rodenhuis C, Pierart M, Horiot J. The addition of a boost dose on the primary tumour bed after lumpectomy in breast conserving treatment for breast cancer. A summary of the results of EORTC 22881-10882 "boost versus no boost" trial. Cancer/ Radiothérapie. 2008 Nov;12(6-7):565-570. https://doi. org/10.1016/j.canrad.2008.07.014

12. Benda RK, Yasuda G, Sethi A, Gabram SG, Hinerman RW, Mendenhall NP. Breast boost: Are we missing the target? Cancer. 200302 03;97(4):905-909. https://doi.org/10.1002/ cncr. 11142

13. Oh KS, Kong F, Griffith KA, Yanke B, Pierce LJ. Planning the breast tumor bed boost: Changes in the excision cavity volume and surgical scar location after breast-conserving surgery and whole-breast irradiation. International Journal of Radiation Oncology*Biology*Physics. 2006 Nov;66(3):680686. https://doi.org/10.1016/j.ijrobp.2006.04.042

14. Fawzy R, Lasheen S, Kamaleldin M, Wessam R, Khallaf E, Moussa M. Tumour bed localisation after oncoplastic breast conservative surgery: A comparative contouring study. J Radiother Pract. 2019;18(1):46-51.

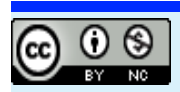

This work is licensed under a Creative Commons AttributionNon Commercial 4.0 International License. 